\title{
Patrimonialización de sitios industriales textiles: más de una década de puesta en valor por las comunidades de Tomé
}

\author{
Patrimonialization of textile industrial sites: \\ more than a decade of valuation by the communities of Tomé
}

\begin{abstract}
Dr. Christian Matus Madrid ${ }^{\mathrm{a}}$, Ms. Paulina Zúñiga Becerra ${ }^{\mathrm{b}}$ \& Dr. Leonel Pérez Bustamante ${ }^{\mathrm{c}}$ anvestigador adjunto Instituto de Estudios Urbanos y Territoriales, Pontificia Universidad Católica de Chile, Chile

matus.christian@gmail.com [orcid.org/0000-0002-4874-7635]

bPontificia Universidad Católica de Chile, Chile pbzuniga@uc.cl [orcid.org/0000-0003-4870-7585]

'Universidad de Concepción, Chile

leperez@udec.cl [orcid.org/0000-0001-6661-6260]
\end{abstract}

\begin{abstract}
RESUMEN
Importantes procesos de revalorización del patrimonio industrial han sido visualizados en la ciudad de Tomé, región del Biobío, Chile. Estas acciones han sido implementadas por más de una década por un movimiento ciudadano que ha estado preocupado por la protección y gestión participativa del patrimonio textil. En este artículo se considera un enfoque metodológico cualitativo para comprender las principales acciones y propuestas adoptadas por la comunidad de Tomé para proteger el patrimonio textil.

Esta investigación propone que hay un patrón distintivo de apropiación patrimonial. Los grupos ciudadanos ofrecen nuevas ideas y prácticas sobre los usos y derechos sociales con respecto a las áreas patrimoniales. Dichas propuestas tienen diferencias con respecto a otras ideas fuertemente centradas en una visión monumentalista.
\end{abstract}

PALABRAS CLAVE: patrimonialización, patrimonio industrial, comunidades, Tomé.

\section{ABSTRACT}

Important processes of revaluation of industrial heritage have been visualized in the city of Tomé, Región del Biobío, Chile. These actions have been implemented for more than a decade by a citizen movement that has been concerned about the protection and participative 
management of the textile heritage. This article considers a qualitative methodological approach to understand the main actions and proposals adopted by the community of Tomé to protect the textile heritage.

This investigation proposes that there is a distinctive pattern of patrimonial appropriation. Citizen groups offer new ideas and practices on social uses and rights with respect to the patrimonial areas. These proposals have differences with respect to other ideas strongly focused on a monumentalist vision.

KEY WORDS: patrimonialization, industrial heritage, communities, Tomé.

\section{INTRODUCCIÓN}

Para entender los procesos de patrimonialización (Rebollo Cruz, 2017) que desarrollan las comunidades textiles, debemos situar sus prácticas de apropiación y uso social del patrimonio industrial en el marco de la nueva dinámica que plantea para los actores locales el actual contexto de desarrollo global. Es relevante considerar que si bien efectivamente los procesos de globalización económica e informacional afectan en forma diferenciada y desigual a los territorios, contribuyendo a segregar entre espacios que acceden a la dinámica global y otros que quedan atrapados en su localización (Bauman, 2017), si se cumplen ciertas condiciones de agencia y participación pueden posibilitar que actores territoriales y comunidades urbanas, anteriormente marginados por las estructuras de poder de la industrialización adquieran un nuevo protagonismo y se empoderen. De este modo apropiándose de su memoria e identidad histórica, las comunidades patrimoniales pueden generar nuevas articulaciones entre lo local y lo global en el marco de la nueva dinámica de desindustrialización (Pagola \& Pérez, 2018).

En efecto, el cambio en la economía política del capitalismo tardío que marca el punto de inflexión de un régimen de acumulación fordista a un régimen post-fordista o de acumulación flexible (Harvey, 1998), y su impacto en la compresión espacio-temporal (Jameson, 1995), en el desarrollo de dinámicas simultáneas de desterritorialización y reterritorialización (García Canclini, 1990), acompañadas por el efecto de las nuevas tecnologías informacionales (Castells, 2015), plantean también una oportunidad para el re-escalamiento de la participación de las comunidades locales en el sistema-mundo (Wallerstein, 2005) del capitalismo o modernidad tardía.

A contrapelo de los planteamientos críticos que sostenían su pérdida definitiva, la identidad cultural (re)aparece en el actual contexto de globalización como un atributo que se potencia y fortalece (Bengoa, 1999; Giddens, 1999). Siguiendo a Castells (2003), el nuevo escenario de la globalización plantea una separación en diferentes marcos temporales del poder y la experiencia, no existe continuidad entre la lógica de la creación de poder en la red global y la lógica de la asociación y la representación en las sociedades y culturas 
específicas. En ese contexto, la base de construcción de sentidos radica en la (re)construcción de identidades colectivas primarias pero no aisladas, sino que hacen uso táctico y estratégico de su relación con actores ubicados en diferentes escalas.

Uno de los principales ejes de transformación del significado de lo patrimonial marca el paso desde una mirada tradicional asociada a la conservación y la monumentalidad a un enfoque socio-cultural que explora en sus usos sociales (García Canclini, 1999) y significados colectivos. Siguiendo a García Canclini (1999), la ampliación en la comprensión del patrimonio cultural,plantea un triple movimiento de redefinición y reconcentración de los discursos referidos al patrimonio. Por un lado, la tendencia a que incluya no sólo la herencia material y pasada de la cultura de cada pueblo sino también los bienes actuales, visibles e invisibles. Por otro, la consiguiente extensión de la política patrimonial de la conservación y administración de lo producido en el pasado, a los usos sociales que relacionan esos bienes con las necesidades contemporáneas de las mayorías, y finalmente, un cambio en el foco de la selección patrimonial que otrora privilegiaba los bienes culturales producidos por las clases hegemónicas y que hoy reconoce el rol que tiene en el patrimonio la cultura popular.

Una clave que plantea el cambio de mirada en la comprensión del patrimonio tiene relación con la reformulación de éste en términos de capital cultural (Bourdieu, 1998), que hace que se pueda entender como un proceso social que "se acumula, se renueva, produce rendimientos de los que los diversos sectores se apropian en forma desigual” (op. cit, 18). En ese marco se puede entender la desigual participación social que han tenido los grupos sociales subalternos, como los obreros y trabajadores que participaron de la cultura industrial, en la construcción de una visión alternativa a la mirada hegemónica del patrimonio industrial, proceso que como abordaremos a través del estudio de caso, comienza a revertirse para constituir un uso social del patrimonio fundado en significaciones diferentes.

En Chile el reconocimiento de lo patrimonial desarrollado por las élites, centralistamente enfocado en el patrimonio urbano santiaguino (Márquez, Rozas \& Arriagada, 2014), se expande a grupos cada vez más amplios de población (Rojas Morales, 2013), dando lugar a movimientos patrimonialistas que luchan por su apropiación social y simbólica, desarrollando procesos de resistencia a la modernización urbana y aportando de esta manera en una democratización del patrimonio (Rojas Alcayaga, 2015). En ese contexto, en las últimas dos décadas, un actor central que da nuevos significados y sentidos al patrimonio son las ciudadanías que contribuyen a integrar su visión sobre los espacios patrimoniales como un elemento a incorporar a la planificación territorial, desarrollando una reapropiación del patrimonio como una herramienta de defensa y gestión territorial que permite levantar una alternativa a procesos de desarrollo urbano que amenazan el futuro de sus comunidades.

En ese marco destacan las experiencias participativas de ciertas comunidades locales que adquieren una capacidad de manejo en los nuevos códigos de poder y contra poder de la sociedad-red (Castells, 2015), que les permite articular una relación desde las escalas intermedias de lo regional y lo nacional hacia vínculos más complejos entre lo local y lo global. 
Este nuevo contexto constituye un espacio de oportunidad para la participación local al generar un margen para que ciertos colectivos territoriales articulen y hagan uso político de los vínculos que pueden establecer entre las diferentes escalas de lo local, regional, nacional y lo global. Siguiendo a Sassen (2007), la pérdida de poder del Estado-Nación plantea la posibilidad para que surjan nuevas formas de poder y político en el nivel subnacional y en el supranacional, indicando que es necesario prestar atención a la configuración de una nueva política civil, donde el espacio intermedio de la ciudad tiene un rol central para la visibilización de las demandas y propuestas de actores locales que antes estaban confinados a la escala nacional.

Continuando esta línea, la noción de "política de escalas" puede ser aplicada para entender cómo los movimientos patrimoniales han reconfigurado su acción política en base al rango de acción territorial que establecen sus movilizaciones en relación a la identidad de su territorio. En ese marco observaremos en las ciudades chilenas como Santiago a los vecinos de antiguos barrios urbanos que empiezan a desarrollar su estrategia territorial apropiándose de la escala de lo céntrico-barrial, reivindicando su identidad y patrimonio como herramienta de defensa ante el impacto de procesos de desarrollo que plantean la preeminencia de una escala más amplia dada por la metropolización.

A modo de ejemplo es posible citar el movimiento del Barrio Bellavista contra el proyecto de Costanera Norte entre 1997 y 2003 (Sagaris, 2014), que logra en base a la reivindicación de una escala de macro-barrio modificar un proyecto que amenazaba su identidad de barrio. Por otro lado, destaca desde el campo propiamente patrimonial el movimiento de defensa patrimonial desarrollado desde 2005 por los vecinos del Barrio Yungay, que reivindican su identidad de barrio céntrico patrimonial en su lucha contra la expansión inmobiliaria (Paulsen, 2014) que posteriormente da origen, en 2010, a la Asociación Chilena de Barrios y Zonas Patrimoniales (Osorio, 2018), actor que reivindicará el derecho de todas las comunidades locales, urbanas y no urbanas, al patrimonio.

Otros autores como Colin (2017), a partir de una aproximación etnográfica al movimiento de defensa del Barrio Matta Sur de Santiago, plantean la centralidad que tienen los afectos y la nostalgia como herramienta de apropiación del espacio urbano en antiguos residentes que comparten una identidad a escala de barrio. Del mismo modo, en Valparaíso se moviliza la ciudadanía para defender los barrios porteños del impacto de la turistificación post-declaratoria como Patrimonio de la Humanidad, generándose movimientos patrimonialistas que impugnan el desarrollo de proyectos de infraestructura de gran escala, apelando a la escala urbana, el derecho a la ciudad y el patrimonio (Rojas \& Bustos, 2015), sin lograr el mismo protagonismo en la gestión del desarrollo en la escala territorial del barrio.

Por su parte, el contexto específico y particular del impacto del cambio económico que gatilló la desindustrialización y cierre de sitios industriales que daban trabajo a gran parte de la población de las ciudades localizadas en la conurbación costera de Concepción, 
región del Biobío, determina un patrón distintivo de apropiación del patrimonio por parte de la ciudadanía regional, que se diferencia de los procesos de defensa y resistencia local desarrollados por los barrios de metrópolis como Santiago y el Gran Valparaíso.

Esta particularidad en la apropiación patrimonial se visibiliza, sobre todo, producto del impacto del terremoto y tsunami del 27 de febrero de 2010 en las comunidades locales de ciudades industriales de la costa del Biobío. La reacción a la catástrofe da pie a un importante ejercicio de revaloración del patrimonio cultural como herramienta de construcción de espacio público y rescate de identidades locales por parte de ciudadanos organizados, los que en ausencia de una política local de gestión patrimonial se constituyen en sí mismos como "sujetos patrimoniales" que reconocen, apropian y protegen su propio patrimonio (Carrión, 2010). Dentro de estos procesos destaca en particular el desarrollado por la comunidad de la ciudad de Tomé- caso de estudio de esta investigación- en relación con la defensa y gestión de su patrimonio, relevando la importancia que para este territorio tuvo y tiene la industria textil (Fig. 1).

Si bien en Chile la mirada tradicional sobre patrimonio industrial se ha centrado en la materialidad (lo monumental), se encuentra aún pendiente relevar las formas de construir patrimonio y habitarlo; desde esa perspectiva cobran importancia las voces de sus principales activadores, los trabajadores y habitantes, tanto del pasado como del presente, de las culturas industriales.

En ese contexto entenderemos -por extensión- como patrimonio industrial tanto la cultura material (arquitectónica, técnica, simbólica, artística, funcional) como la inmaterial, es decir, los saberes, mentalidades, valores y subculturas vinculados a los agentes que protagonizan la extracción, producción y reproducción en las sociedades industriales y sus culturas del trabajo (Cano, 2007; Álvarez, 2008; Homobono, 2008). Siguiendo lo anterior nos aproximaremos al patrimonio industrial también como un testimonio de lo cotidiano, una memoria del trabajo y del lugar (Álvarez, 2008).

Interesa relevar bajo esta línea cómo la comunidad local de una ciudad sometida a fuertes procesos de desindustrialización en una región de pasado industrial, como la del Biobío, se apropia del valor y significado de sus sitios industriales textiles para hacer frente a los desafíos de su desarrollo, dotando al patrimonio industrial de un doble significado: por un lado, su uso social como herramienta de defensa a procesos de metropolización que las amenazan y, por otro, su apropiación como un recurso que dota al patrimonio industrial de un sentido de futuro.

La apropiación del patrimonio industrial que hacen las comunidades de Tomé se produce en el contexto del auge de nuevas formas organizacionales, saberes, experticias y uso de nuevas plataformas de comunicación, generando nuevas concepciones y prácticas de gestión patrimonial. Aprendizajes sociales que es necesario procesar y analizar para redefinir y actualizar a partir de sus experiencias cómo se entiende actualmente el patrimonio industrial. 


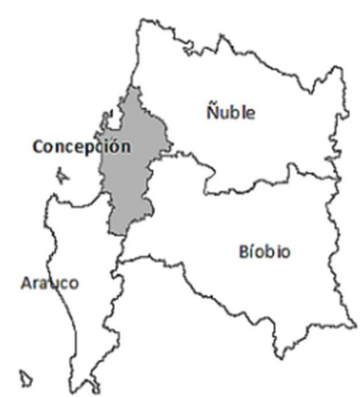

Provincias, Región del Biobío

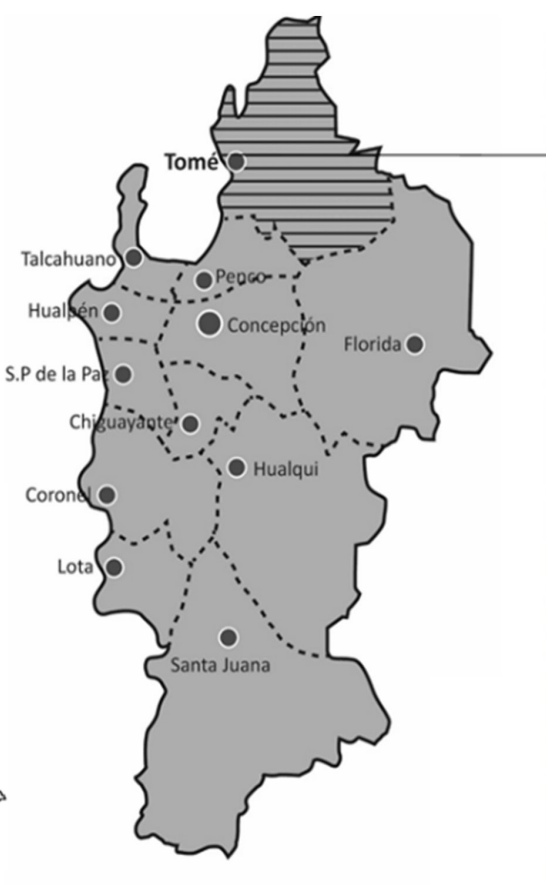

Provincia de Concepción-Comuna Tomé

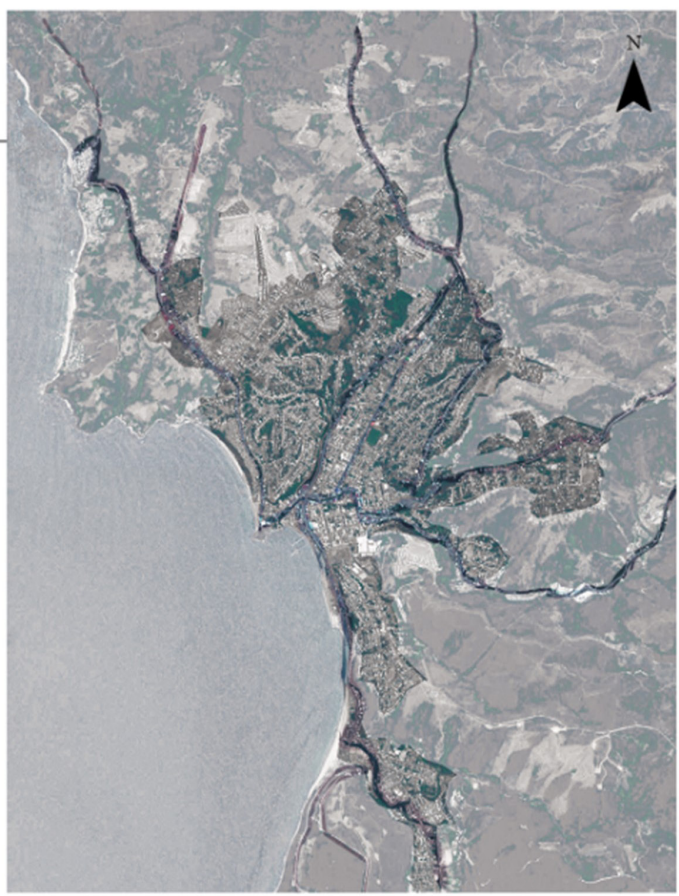

Planimetría Ciudad de Tomé

Fig. 1. Mapa de Tomé en su contexto geográfico. Fuente: Elaboración propia en base a Villagra (2014).

Siguiendo lo anterior, el énfasis de este paper se centrará en desarrollar un análisis de los procesos de re-apropiación y reinterpretación de espacios industriales y sociales desarrollados por comunidades representativas de los modos de vida construidos en torno a la industria textil. Se plantea indagar los procesos de puesta en valor del patrimonio por parte de la comunidad de la ciudad de Tomé. Interesa dar cuenta de modo específico ¿cómo y desde dónde construyen su visión de patrimonio las comunidades de Tomé? Esta pregunta es central para entender también el sentido que asume el patrimonio como herramienta de reflexión colectiva sobre el pasado, presente y futuro en territorios que se encuentran sometidos a fuertes procesos de transformación (Aliste, Almendras \& Contreras, 2012), que han modificado los modos de vida de localidades cuya identidad se construyó en función de un pasado productivo de carácter industrial y que hoy parecen percibir la ausencia de un proyecto de futuro que los haga partícipes.

La pregunta general de investigación tiene que ver con conocer y comprender qué sentido tiene el rescate y revalorización patrimonial industrial para los actores territoriales, indagando cómo la comunidad específica de Tomé construye nuevas visiones y significaciones sobre éste y que no siempre son consideradas como parte de la política pública local y nacional que aborda el patrimonio industrial en Chile.

Para ello, el artículo se divide en tres secciones: 1) metodología, que da cuenta del abordaje y técnicas consideradas para la recopilación de información en esta investigación, 2) contexto 
socioterritorial, que evidencia los procesos de industrialización y desindustrialización en la ciudad de Tomé, y 3) los procesos de patrimonialización asociados al patrimonio industrial textil, donde se plasman las iniciativas de puesta en valor, sus proyecciones y tensiones.

\section{METODOLOGÍA}

El estudio en que se basa el presente artículo se estructuró como una estrategia de investigación de corte cualitativo para sistematizar y comprender los procesos de patrimonialización desarrollados en torno al patrimonio industrial textil de la ciudad de Tomé.

El trabajo de campo fue desarrollado durante los meses de febrero y marzo de 2018, período en que se efectuó un reconocimiento del área de estudio, la elaboración de un catastro patrimonial de los barrios y vestigios industriales actuales de la ciudad para posteriormente desarrollar entrevistas semiestructuradas a informantes claves.

Para focalizar a quiénes entrevistar se realizó un muestreo cualitativo mediante la técnica de cadena o redes, es decir, se identificó en primera instancia informantes claves, y posteriormente se les preguntó por algún contacto que pudiese ampliar y/o complementar la información hasta encontrar el punto de saturación (Hernández, Fernández \& Baptista, 1998). En este marco, se entrevistó un total de 20 actores locales relacionados con los procesos de patrimonialización o puesta en valor liderados por la comunidad desde el 2008 hasta la actualidad, con el propósito de levantar información sobre las experiencias y significados que los habitantes poseen acerca del patrimonio industrial textil.

En ese contexto se consideraron tres categorías de entrevistados: a) ocho actores ciudadanos: dados por organizaciones directamente relacionadas con la defensa del patrimonio textil como Consejo Comunal para el Patrimonio Tomé, Mesa Ciudadana por el Patrimonio de Tomé, Corporación La Fábrica y Corporación de ex trabajadores textiles de Tomé; b) cuatro actores comunitarios: Junta de vecinos Bellavista y Los Tilos, habitantes, vecinos, historiadores locales, que residen hace más de diez años en la ciudad; y c) seis ex trabajadores textiles de las fábricas Italoamericana de Paños (FIAP), Sociedad Nacional de Paños y Fábrica Bellavista-Oveja Tomé.

Complementariamente se realizaron entrevistas a los encargados de patrimonio de la Municipalidad-SECPLA y a la coordinadora del Equipo Quiero Mi Barrio Bellavista.

En relación a las fuentes secundarias, se desarrolló una revisión exhaustiva de artículos científicos y libros de historia local para comprender el proceso de industrialización y desindustrialización acaecido en Tomé en base a la actividad textil, y además de ello, una revisión de producciones culturales, tales como archivos de prensa, afiches, marchas, redes sociales, etc., que permitieran identificar el discurso de los actores involucrados en los procesos de patrimonialización.

Por último, la sistematización y análisis de la información se llevó a cabo a través de matrices de análisis cualitativo que permitieron el ensamblaje y triangulación de las fuentes primarias y secundarias. 


\section{CONTEXTO SOCIOTERRITORIAL}

\section{La "época dorada" de la industria textil en Tomé}

La ciudad de Tomé se encuentra emplazada en la bahía de Concepción, región del Biobío. Como ciudad puerto se ha caracterizado por su vocación industrial, en donde las textiles han sido la expresión más notable e intensa de la actividad fabril (Cartes et al. 2012, p. 19). Es así como desde la segunda mitad del siglo XIX comienzan a posicionarse en Tomépor su localización geoestratégica como ciudad costera- las reconocidas fábricas textiles. En la entrada sur de la ciudad se instaló en el año 1865, la Fábrica de Paños Bellavista, que fue pionera en el rubro textil a nivel nacional; posteriormente, en 1913, se establece en el centro, la Fábrica Nacional de Paños (o Sociedad Nacional de Paños Oveja) y adyacente a ésta, se fundó más tarde en 1932, la Fábrica Ítalo Americana de Paños (FIAP) (Fig. 2) (Corvalán, 1999; Cartes et al. 2012).

El posicionamiento de este rubro debe ser comprendido además en el marco de un proceso mucho más amplio, que responde al contexto político y económico que se estaba gestando por medio de la Política de Sustitución de Importaciones (Hernández, 1983; Correa et al. 2001). Este modelo de industrialización fue de la mano a su vez con un proceso de urbanización, que fortaleció gradualmente a Tomé como una ciudad industrial, generándose "la clásica migración campo ciudad (...) se vienen desde el interior muchas familias y comienzan a poblar principalmente la zona de Bellavista" (GO, Sector centro Tomé1).

El aumento del crecimiento poblacional en Tomé gatilló en un problema habitacional que se tradujo en la proliferación de conventillos y asentamientos informales. Ante este panorama, las fábricas comenzaron a hacerse cargo de dicha situación por medio de la construcción de barrios textiles aledaños a sus dependencias: "después de la instalación de estas fábricas se vivió un crecimiento demográfico y un auge económico que se tradujo en la creación de nuevos barrios fabriles, la construcción de edificios de equipamiento y el crecimiento hacia los cerros" (Pérez \& Lagos, 2014, p. 206).

Estas construcciones instalaron modelos urbanísticos europeos y además de ello, acrecentaron la relación de dependencia industria-barrio que facilitó el control totalizador de los trabajadores tanto en los aspectos urbanos (la empresa proveía de los servicios y equipamientos básicos), como también por la estructura social a los que éstos se veían sujetos, dada la alta estratificación y segregación social de la época (Villagra, 2014; Venegas Valdebenitos \& Morales Barrientos, 2017).

La construcción de estos barrios fue gradual en el tiempo, comenzando en el sur de Tomé en la zona denominada como Barrio Bellavista en 1905, para finalizar en la década del cincuenta con la urbanización del cerro La Pampa a través de la Población FIAP y Carlos Mahns (Fig. 3) (Villagra, 2014).

Los entrevistados fueron identificados con sus iniciales y área geográfica de pertenencia. 


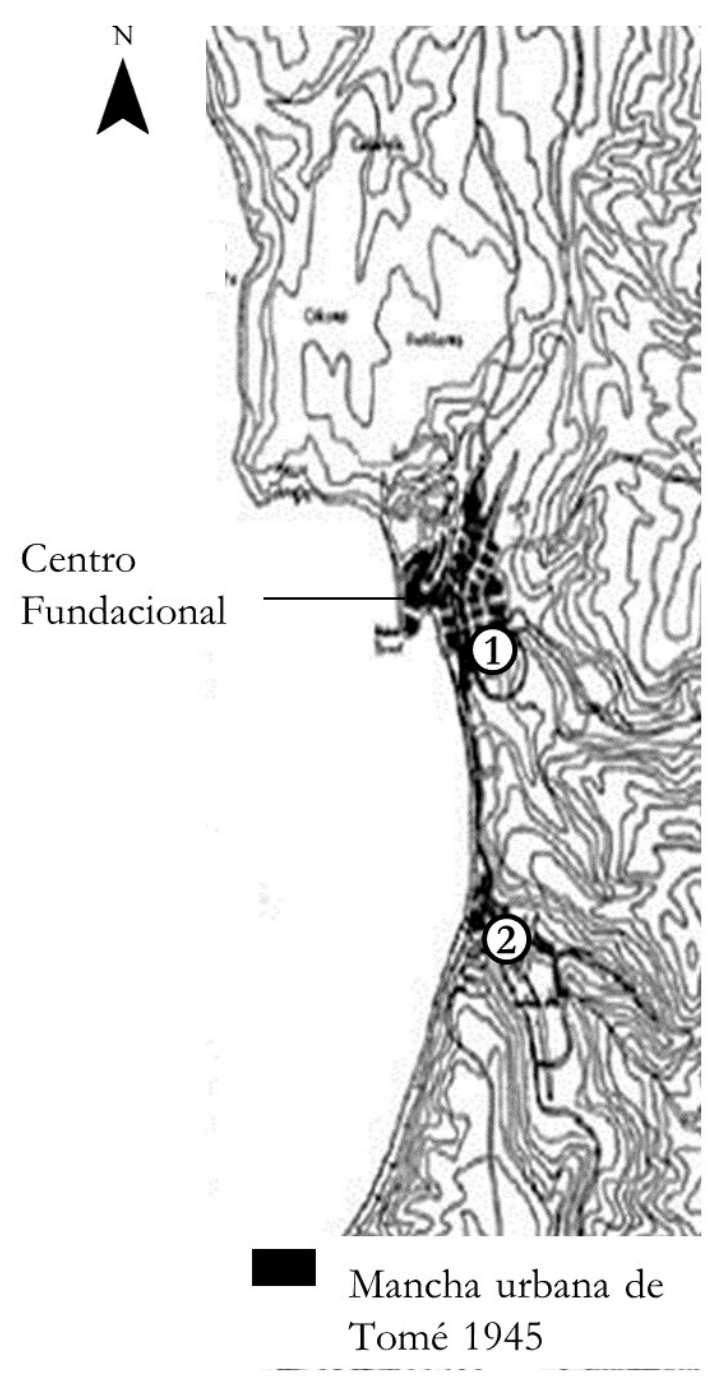

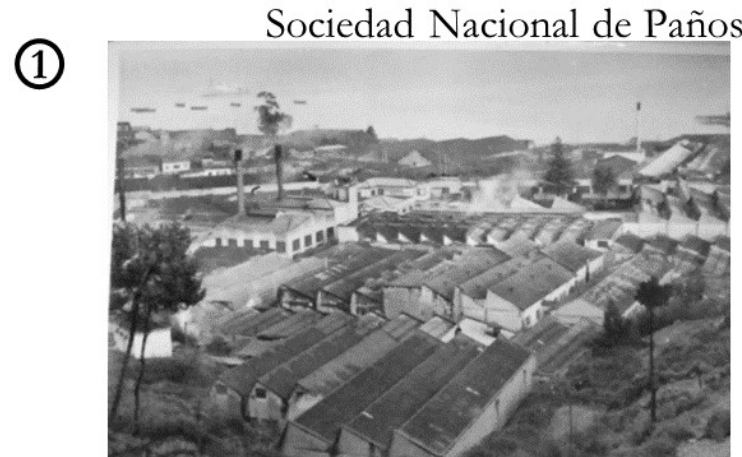

Fábrica FIAP
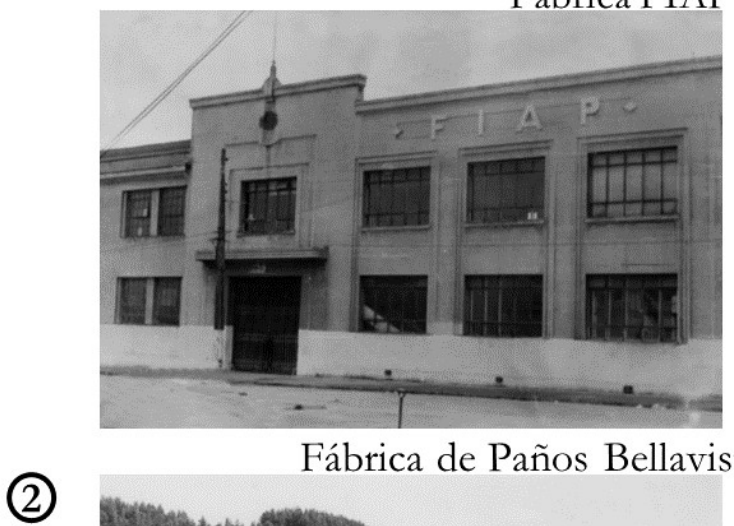

Fábrica de Paños Bellavista

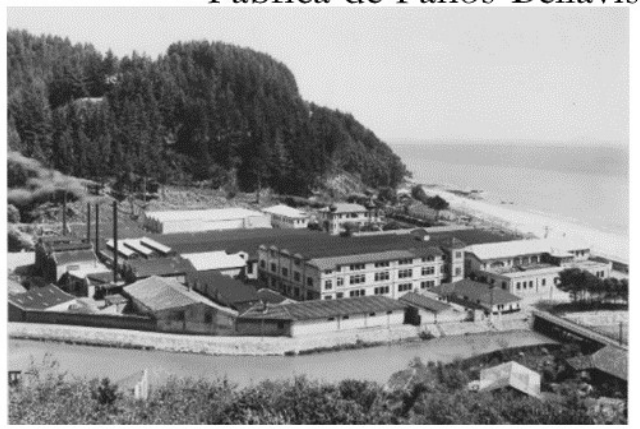

Fig. 2. Fábricas textiles en Tomé.

Fuente: Elaboración propia en base a Ilustre Municipalidad de Tomé (2016), y fotografías de: Museo Histórico de Tomé (2018), Quiero Mi Barrio (2018).

Más allá de la construcción de barrios industriales, las fábricas procuraron otorgar equipamientos que permitieron esculpir el tejido social de Tomé. La actividad industrial conformó nodos productivos, que ampliaron el área de influencia desde la esfera fabril al territorio (Álvarez, 2010; Venegas Valdebenitos \& Morales Barrientos, 2017). Desde esta perspectiva, a partir del treinta comienzan a conformarse los primeros sindicatos de trabajadores, y en la década del cincuenta con mayor potencia, la construcción de instalaciones socioculturales, educacionales, comerciales, médicas, sociales, etc. Situación que da cuenta de la importancia de estas instalaciones y su influencia en la conformidad de una identidad tomecina. 

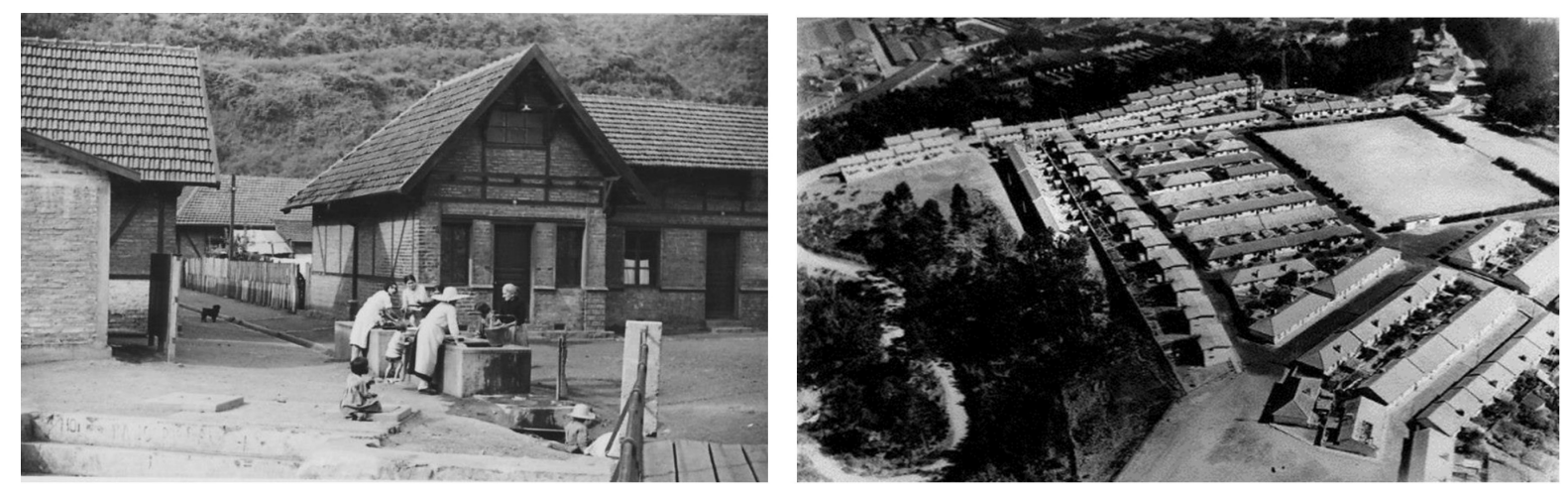

Fig. 3. Población La Rana, Barrio Bellavista y Carlos Mahns.

Fuente: Museo Histórico de Tomé (2018).

\section{La desindustrialización: ocaso del apogeo textil en Tomé}

Desde el sesenta en adelante comienza a identificarse una reestructuración interna de las empresas textiles, que en conjunto con el panorama socioeconómico nacional e internacional, detonan en una serie de cambios, cuyo impacto se traduce en el proceso de desindustrialización.

Tras la llegada al poder de la Unidad Popular en la década del setenta, el estancamiento de la industria textil comienza a hacerse evidente. Las fábricas pasan a manos del Área de Protección Social (APS), siendo expropiadas por el Estado, cambiando sus modalidades de administración y además de ello, no contando con la solvencia económica para poder mantenerse en el tiempo. Esta situación, sumada a la instalación de competencia que vendía productos más económicos, escasa inversión en tecnología, bajos niveles de productividad, aumento de la inflación, nula posibilidad de optar a créditos, por nombrar algunos factores, fueron los garantes de una crisis industrial a nivel nacional (González \& Vera, 2009; Pérez et al. 2010).

Posteriormente, en 1973 con la dictadura militar, se instala un sistema económico de libre mercado, que en definitiva se traduce en un rol menos activo del Estado y en la desestabilización de las fábricas, siendo aún más perjudicadas con la crisis de principio de la década del ochenta: "que hundió más a las industrias, provocando en ciudades eminentemente textiles, notables tasas de desempleo" (González \& Vera, 2009, p. 50). En 1979, la fábrica FIAP es liquidada y, en 1982, la Sociedad Nacional de Paños es declarada en quiebra, fusionándose con Bellavista para conformar la denominada "Fábrica Bellavista-Oveja Tomé" (Cartes et al. 2012).

El cierre de las fábricas no sólo trajo consecuencias económicas para la fuerza laboral, sino también una ruptura en los modos de vida asociados a estos espacios productivos (Benito del Pozo, 2002). Muchos trabajadores luego de la quiebra de sus empresas tuvieron que cambiar de rubro, siendo esta tarea particularmente difícil dada la especialización laboral de los textiles.

El fin del período paternalista, la migración en búsqueda de nuevas oportunidades laborales, la desarticulación de las relaciones sociales al interior de los barrios textiles, 
fueron otras de las consecuencias que se vislumbraron durante este proceso. Además de ello, se evidencia la proliferación de vestigios industriales, en donde las antiguas fábricas y sus dependencias comienzan a configurarse como elefantes blancos, carcasas, que se encuentran en obsolescencia funcional o que han sido demolidas, traspasadas a manos de privados y que sólo se traducen hoy en día en un alto sentimiento de añoranza por parte de sus habitantes y sobre todo de sus trabajadores.

A su vez, es relevante destacar que si bien por una parte las huellas de la desindustrialización provocaron un período de obsolescencia, destrucción y abandono de estas instalaciones, también motivaron en procesos de incipiente valorización de este pasado productivo. En definitiva, de la destrucción comenzó una necesidad comunitaria de otorgar sentido y poner en valor estos vestigios industriales textiles.

\section{PROCESOS DE PATRIMONIALIZACIÓN CIUDADANA EN TOMÉ (2008-2018)}

A continuación se realizará una descripción y reflexión acerca de los procesos de patrimonialización de los vestigios asociados a la industria textil de Tomé. Para ello, se han considerado dos temporalidades: 2008-2014, donde surgen las primeras iniciativas relacionadas a la protección del patrimonio en la ciudad, y 2014-2018, período en que se efectúa el proceso de declaratoria como Monumento Histórico de la Fábrica Bellavista-Oveja Tomé liderado por la sociedad civil.

\section{Primeras iniciativas de patrimonialización en Tomé (2008-2014)}

A partir de los noventa se reconoce en Tomé un incipiente proceso en que la sociedad civil comienza a apropiarse de su identidad como una herramienta o mecanismo de defensa ante la amenaza de los impactos de la metropolización, entre ellos: la expansión y renovación urbana, el aumento de nuevos proyectos inmobiliarios, los cambios de uso de suelo, etc., que constituyen factores altamente amenazantes para los bienes e inmuebles de carácter patrimonial (Pérez \& Matus, 2017). Desde esta perspectiva, una de las primeras iniciativas de protección patrimonial en la ciudad de Tomé, surge al alero del Plan Regulador Comunal del año 2008, donde se reconocen como Zonas de Conservación Histórica (ZCH), los barrios de Bellavista y Carlos Mahns, y como Inmuebles de Conservación Histórica, las iglesias pertenecientes a ambos sectores (Ilustre Municipalidad de Tomé, 2016).

No obstante, no sería hasta el año 2009 cuando se vislumbraría el primer proceso de patrimonialización liderado por la comunidad tomecina a raíz de un conflicto urbano generado por la remodelación del trazado de la Plaza de Armas Arturo Prat. Este hito significativo, gatillaría en la creación de un movimiento social en pos de proteger el diseño original del espacio público, creándose para ello, el Consejo Comunal para el Patrimonio Tomé, que corresponde a un grupo jurídicamente organizado, cuyo propósito es dar "cumplimiento a los objetivos de defensa, 
protección y difusión de los valores patrimoniales, tanto materiales como inmateriales, así como culturales, naturales, arquitectónicos y sociales" (Patrimonio Tomé, 2014, p. s/n).

El Consejo constituyó una instancia de participación para diversos actores, entre ellos: líderes vecinales, profesionales, historiadores locales, estudiantes, académicos, artistas, ex trabajadores textiles, etc., cuyo fin es luchar por la defensa del patrimonio tomecino. Desde esta perspectiva, el Consejo fue la primera organización en donde la comunidad "empieza a hablar del patrimonio, el patrimonio como lo construido, el patrimonio como lo que pertenecemos, lo que hemos heredado" (GO, Sector centro Tomé); siendo necesario por lo tanto comenzar a protegerlo y valorarlo ante su gran vulnerabilidad. La construcción de nuevas edificaciones en ex dependencias fabriles por la acción inmobiliaria y la demolición del Inmueble de Conservación Histórica, la Casa Hinrichsen, evidenciaron la insuficiente protección de los valores patrimoniales en ausencia de un plan de gestión Municipal (Villagra, 2014; Pérez \& Matus, 2017).

De acuerdo a lo anterior, en el año 2013 se efectuó la primera declaratoria de Monumento Nacional en categoría de Monumento Histórico para el Deportivo y Cine Bellavista. Este proceso fue liderado por la Municipalidad, el Consejo y otras organizaciones de la sociedad civil, que manifestaron a través del Decreto $\mathrm{N}^{\circ} 46$ la necesidad de poner en valor los aspectos históricos, arquitectónicos y sociales del deportivo, por su rol como equipamiento público y testimonio del desarrollo sociocultural generado en torno a la Fábrica Bellavista (CMN, 2013). Por otra parte, también se realizó el programa Quiero Mi Barrio en el sector de Bellavista durante el 2015, con el fin de potenciar tanto el patrimonio material como inmaterial asociado a la actividad textil.

Estas acciones plasman que la necesidad del rescate de identidades locales y el empoderamiento comunitario fueron aspectos claves en el inicio de un interés tanto de organismos públicos como de la sociedad civil para para salvaguardar el patrimonio industrial de Tomé: "empezaron a aparecer hartas personas que dijeron si po, acordémonos lo que es patrimonio, a recordar las cosas que hacíamos cuando chico. La gente se empezó a dar cuenta que las cosas tenían un valor histórico por su memoria colectiva" (RN, Sector centro Tomé). En este contexto, cabe destacar que estas iniciativas alcanzaron su máximo esplendor con el proceso de declaratoria de la Fábrica Bellavista-Oveja Tomé como Monumento Histórico.

\section{La declaratoria de la Fábrica Bellavista-Oveja Tomé (2014-2018)}

Durante el año 2016 el proyecto inmobiliario del Grupo Sabat actuales dueños de la Fábrica Bellavista-, presentaron una propuesta al Municipio para realizar una modificación del Plan Regulador de Tomé con el fin de cambiar el uso de suelo de esta instalación, pasando de industrial a inmobiliario. En dicha solicitud, se pretendía levantar departamentos, proyectando construir $180 \mathrm{mil} \mathrm{m} 2$, pero manteniendo las fachadas principales y la torre del reloj por ser consideradas icónicas (Álvarez, 2016). Anterior a este panorama, el Consejo en conjunto con la Municipalidad, ya se encontraban desde el 2014 interesados en llevar a cabo la declaración de Monumento Histórico para Bellavista: 
Nos encontrábamos ante una situación que la Fábrica Bellavista quería ser vendida. Primero quería ser loteada, y después se presentó un proyecto de los mismos operadores de la fábrica al Municipio, para demoler y construir edificios de departamentos como los que tenemos al ingreso de Tomé. Eso hizo otro llamado ciudadano, nuevamente la comunidad, liderada por el Consejo decide reunirse y pensar en cómo detener eso (GO, Sector centro Tomé).

Surge bajo este panorama, la Mesa Ciudadana por el Patrimonio de Tomé como una segunda organización enfocada netamente en la declaratoria de la fábrica: "en este grupo nиеvo nosotros queremos futuro, queremos desarrollo, pero no queremos desarrollo olvidándonos del pasado. Para nosotros el sueño y nuestra misión, es que ese inmueble, que es lo único que nos queda para identificarnos, no se destruya" (SV, Barrio Bellavista). La Mesa hizo extensiva a la comunidad su propósito de proteger la fábrica, recuperando firmas, enviando cartas a las autoridades, organizando asambleas con diversos actores, convocando juntas de vecinos, etc., para dar visibilidad y difusión al conflicto a través de todas las plataformas e incluso haciendo partícipes a organizaciones fuera del contexto local (Fig. 4).

El proceso de declaratoria fue complejo, por una parte se encontraban los intereses comunitarios, que en su mayoría apoyaban la iniciativa de proteger la fábrica; por otro, la Municipalidad, que funcionaba de interlocutor y gestor; y por último, los intereses privados que pretendían hacer usufructo del terreno. No obstante, pese a las dificultades, Bellavista

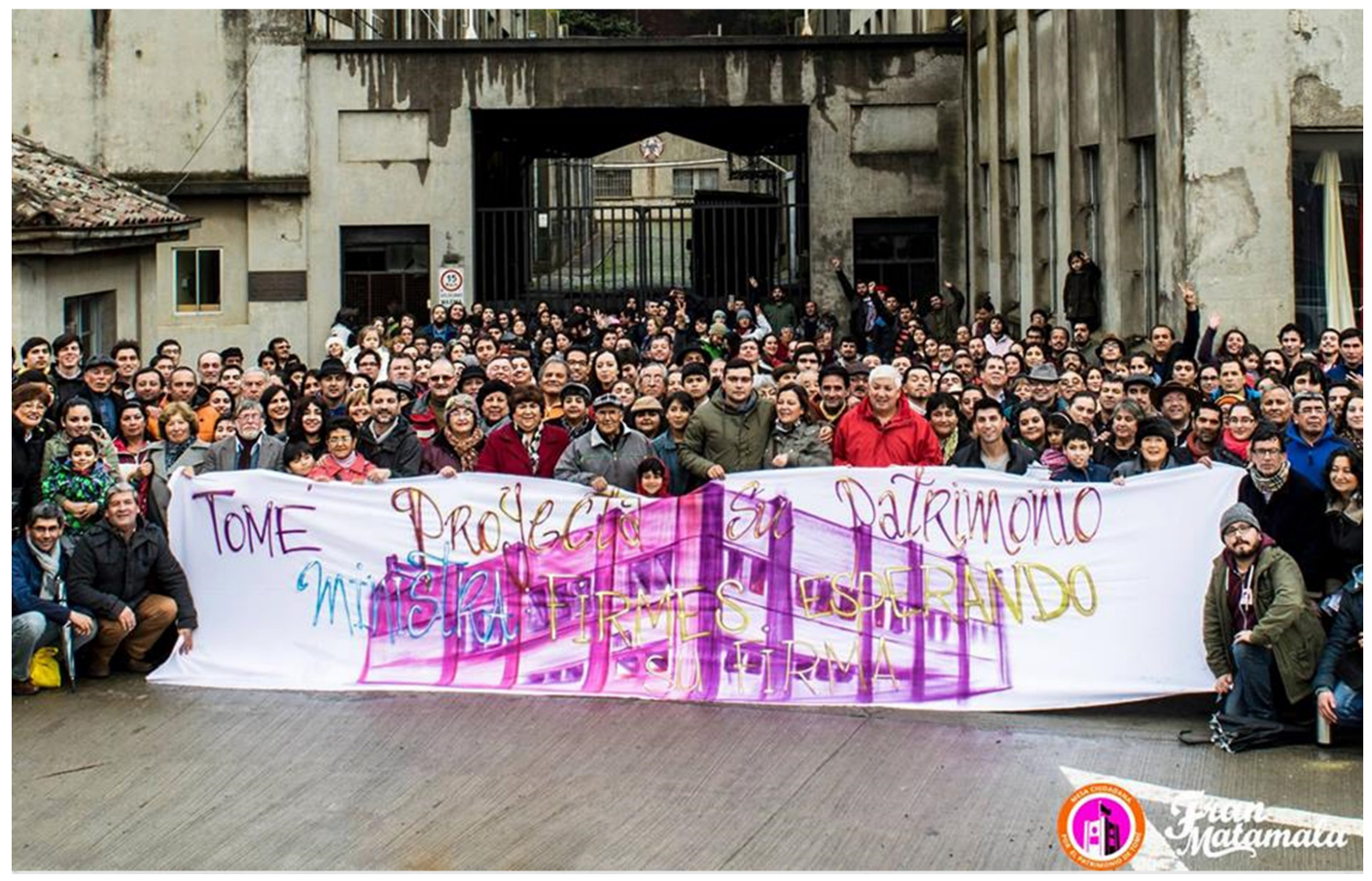

Fig. 4. Actividades Mesa Ciudadana por el Patrimonio de Tomé. Fuente: Mesa Ciudadana por el Patrimonio de Tomé, Matamala (2016). 
fue finalmente declarado Monumento Histórico el 13 de abril de 2016, mientras que su decreto fue firmado por la ministra de educación un año después, aun tras el recurso de inaplicabilidad que solicitaron los dueños de la fábrica ante el Tribunal Constitucional en contra de su declaratoria (Cifuentes, 2017): "fue una declaratoria muy singular, porque era una ciudadanía que estaba defendiendo una propiedad privada, un inmueble, que quizás en lo arquitectónico no es pleno, pero en la memoria era parte de nuestro ADN social como tomecino" (CR, Sector centro Tomé).

El triunfo de la declaratoria de Bellavista consolida el poder de la fábrica como "un tótem cultural" (CR, Sector centro Tomé), cuya importancia se manifiesta en los valores identificados en el Decreto $\mathrm{N}^{\circ} 166$; entre ellos: sus aspectos históricos, por ser reflejo de los procesos de industrialización y desindustrialización, siendo reconocida por la calidad de sus paños como un polo de desarrollo económico local; sus aspectos urbano-arquitectónicos, por constituir una infraestructura cuya morfología está en función del complejo proceso de producción de telas y que contaba con tecnología de avanzada para la época; y por último, por ser un hito para la memoria social y conformarse como un vestigio material/simbólico de la vida cotidiana de los tomecinos (CMN, 2017) (Fig. 5).

Tras la declaratoria de la fábrica, -primer objetivo de la Mesa del Patrimonio-, comenzó a cuestionarse la manera en que ésta debería ser administrada en el tiempo para poder plantear formas de recuperación efectiva:

La meta más inmediata es lograr trabajar en conjunto: fábrica, comunidad, Municipio y elaborar un plan de gestión. Porque el inmueble ya está protegido pero aún se ve un cierto deterioro, se ve poca voluntad de querer presentar nuevas ideas o de hacer un proyecto de gestión en torno al inmueble. Y eso es lo que se quiere hacer, ver la posibilidad de expropiación, o trabajar en conjunto con quienes sean los propietarios en un espacio abierto para la comunidad, para Tomé y también para la cultura (GO, Sector centro Tomé).

En este marco es donde se crea en el año 2018 la Corporación La Fábrica, que busca desde su estructura legal, ser parte de la administración del edificio y además de ello, enfocarse exclusivamente en definir el uso que se dará al espacio. En la actualidad, el futuro de la fábrica está supeditado a las voluntades de las acciones públicas y privadas, que entran en disenso con los intereses comunitarios, y es por ello que las ideas de desarrollar actividades en la fábrica se manifiestan diversas e inciertas:

Va depender de la coordinación de fuerzas sociales y la forma en que nosotros podamos influenciar a distintas autoridades. Los sueños son hartos, yo lo único que me atrevo a decir es que son 44 mil m2 edificados en la actualidad, no existe ningún tótem de esa naturaleza en Chile, por tanto, el espacio y las cosas que puedes hacer ahí son diversas, no tiene que pensarse en un solo rubro (...) (CR, Sector centro Tomé). 

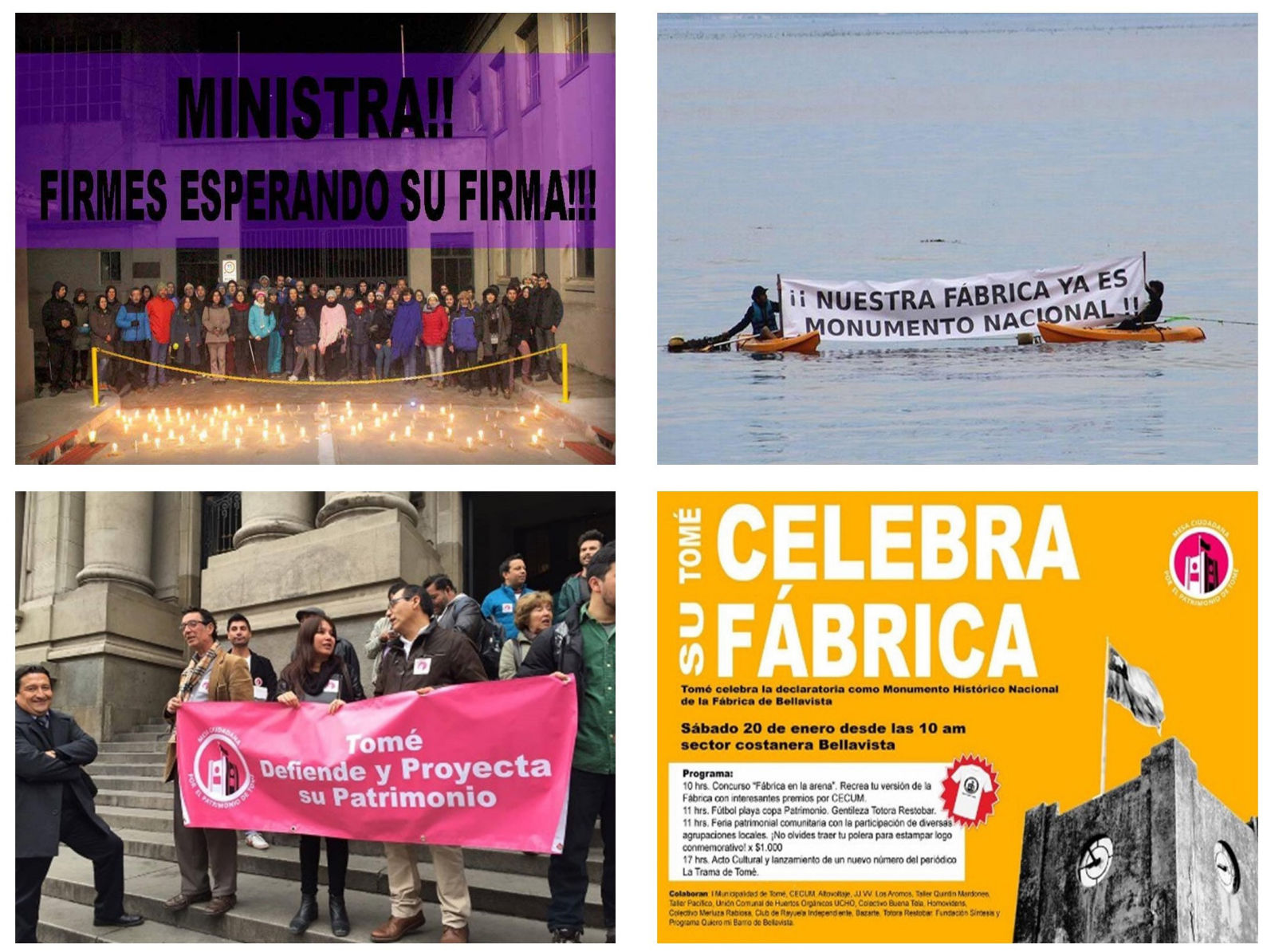

Fig. 5. Declaración Monumento Histórico Fábrica Bellavista.

Fuente: Mesa Ciudadana por el Patrimonio de Tomé (2017).

De acuerdo a lo anterior, actualmente, se plantean importantes desafíos en temas de planificación territorial y articulación de actores, ya que se requieren de estrategias urbanas eficientes para el manejo y gestión del patrimonio industrial de Tomé: "la fábrica es una oportunidad que se tiene y ahí está, depende de los que están, los que hacen las políticas y esa es una debilidad" (CR, Sector centro Tomé). Un elemento clave en este marco, recae en la responsabilidad municipal, que es visualizada por algunos entrevistados como un organismo que carece de las capacidades técnicas y económicas para colaborar en el proceso: "la autoridad no está muy movida en el tema, en el discurso sí, pero en los hechos no (...) no existe un programa o planificación que efectivamente ayude a proteger el patrimonio, como lo que existe acá que es el patrimonio textil" (AP, Barrio Bellavista).

En definitiva, la patrimonialización en Tomé resulta interesante dado que ha sido un proceso multiescalar donde no sólo los especialistas se hacen cargo del patrimonio, sino también la comunidad local se posiciona como el principal agente que motiva la defensa y reconocimiento de los valores materiales e inmateriales como una fuente que permite fortalecer la identidad local 
y memoria colectiva de los habitantes tomecinos (Ortiz, 2004; Dormaels, 2012).

A su vez, es relevante destacar que a través de estos procesos es posible evidenciar el tránsito en la concepción de los inmuebles industriales, que han pasado de ser percibidos como fragmentos sin uso aparente, a poseer un valor intrínseco, estableciéndose como recursos patrimoniales, que pueden ser reconvertidos, resignificados y reutilizados con fines diversos (Benito del Pozo, 2002). La Fábrica Bellavista se posiciona en este sentido como un bien patrimonial, pero que pese a su importancia aún hoy en día es posible evidenciar conflictos y movilizaciones asociados a su grado de protección (Fig. 6):

Interpelamos a que el Estado adquiera la Fábrica de Bellavista-Tomé; y a toda la comunidad, a rearmarse y adherir en defensa de un lugar que encarna tanto nuestra historia e identidad como la posibilidad de un proyecto de desarrollo productivo y cultural. Pese a la declaratoria, la fábrica no logra estar protegida de las acciones de los empresarios que han buscado desmantelar la industria textil para instalar un negocio inmobiliario que además significaría demoler el recinto y atentar contra el valor de nuestra memoria (Mesa Ciudadana por el Patrimonio de Tomé, 2018).

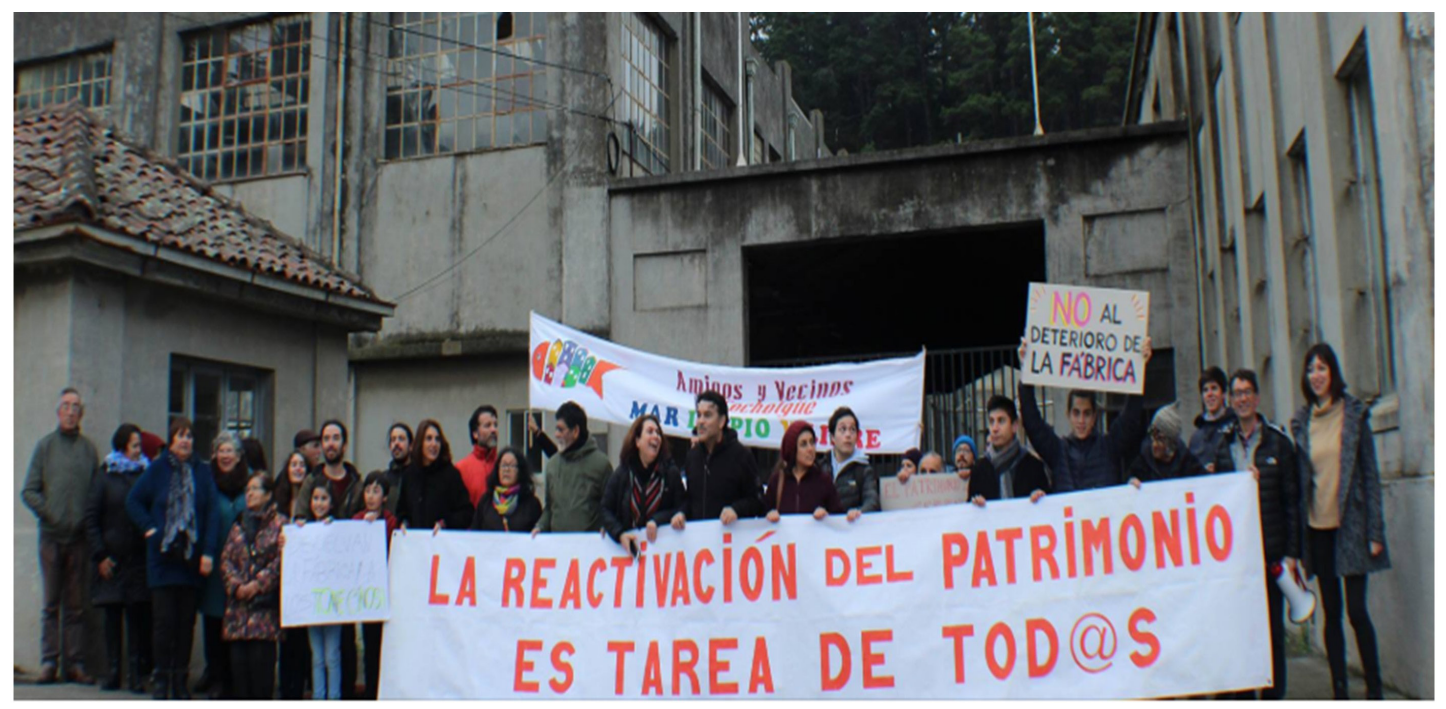

\section{Ante nuevas gestiones de Luksic en el TC: Organizaciones ciudadanas piden al Estado compra de la Fábrica de Bellavista-Tomé}

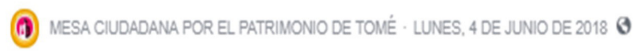

Fig. 6. Movilización de ciudadanos por gestiones de Lucsik en Tribunal Constitucional. Fuente: Mesa Ciudadana por el Patrimonio de Tomé (2018). 


\section{CONCLUSIONES}

El estudio de caso planteado nos permite constatar que la patrimonialización desarrollada por la comunidad textil forma parte de un proceso de "selección patrimonial" donde se elige resguardar y poner en valor sólo algunos atributos materiales e inmateriales de un patrimonio más amplio. De esta forma el movimiento patrimonial de Tomé selecciona estratégicamente para su uso social, un espacio particular del universo más amplio de sitios industriales, centrando sus esfuerzos por defender, activar y proyectar específicamente el patrimonio relacionado con la Fábrica Bellavista-Tomé. En ese sentido la fábrica es percibida transversalmente como un componente central de su experiencia de lo industrial, que cristaliza su memoria colectiva e identidad erigiéndose como un símbolo (el "tótem cultural”) representativo del pasado textil de la ciudad.

Sin embargo, a pesar de reconocerse por medio de las entrevistas un sentimiento de pertenencia hacia otros vestigios industriales tales como las fábricas FIAP y Sociedad Nacional de Paños, éstas no han sido protagonistas de procesos similares de valorización, presentándose más bien en un estado avanzado de obsolescencia funcional.

Desde la perspectiva de la Mesa Ciudadana por el Patrimonio de Tomé, la gestión del patrimonio industrial de la ciudad, simbolizada en la fábrica, debe plasmarse en un enfoque de futuro que considere la revitalización de sus instalaciones a través de proyectos de desarrollo productivo y cultural que potencien la economía local. El trabajo de la Mesa permite constatar que si bien existen categorías de protección patrimonial para inmuebles y barrios industriales textiles en Tomé, ninguno de ellos cuenta actualmente con un plan de gestión y/o proyecto que efectivamente impulse este recurso. La falta de planes de financiamiento, las deficientes competencias públicas y la descoordinación de intereses entre actores públicos, privados y comunitarios, se identifica como un importante desafío para la protección del patrimonio industrial (Sabaté, 2004; Irarrázaval, 2017).

Sumado a lo anterior, cabe destacar que pese a contar con algún grado de protección, el patrimonio se encuentra vulnerable al accionar de los privados y a los cambios en los Planes Reguladores Comunales (PRC), conformando un panorama desalentador como sucede hoy en día con Bellavista Oveja Tomé ante la negativa de los dueños del inmueble en que éste sea reutilizado por la comunidad, habiendo presentado a la fecha dos requerimientos ante el Tribunal Constitucional para detener la puesta en práctica de la declaratoria, aduciendo que ésta constituye requerimientos expropiatorios (Requerimiento Tribunal Constitucional, 2017), poniendo así en tela de juicio todo lo avanzado por la ciudadanía en términos patrimoniales.

En este contexto es donde se evidencia una tensión fundamental entre la comunidad que reclama su derecho al patrimonio como un elemento legítimo y de resistencia considerando los valores inmateriales, la historia, la identidad, la memoria colectiva asociada a la industria textil, y el "derecho a la propiedad" reivindicado por los dueños del inmueble. 
De lo anterior se deriva un hecho no menor, que el patrimonio industrial reivindicado por la comunidad cuenta, dentro de la Ley de Monumentos Nacionales 17.288 (1970), con una, aún más débil protección legal, que otros espacios urbanos reivindicados por otras comunidades como zona típica, ya que escapa de la visión clásica del patrimonio en su noción monumental incluyendo tres dimensiones que no siempre son consideradas en su gestión: el aspecto material, simbólico y territorial (Ibarra \& Bonomo, 2012, pp. 50, 53). Bajo este contexto, es clave comprender que en el caso de Tomé los procesos productivos asociados modelaron y configuraron paisajes de tipo industrial, que comprenden tanto el patrimonio material como inmaterial, siendo este último al que se le presta menor atención desde el ámbito normativo (Ibarra en Rojas, Carvajal \& Ortega, 2015, p. 18; López, Bisbal \& Aroztegui, 2015).

No obstante lo anterior, el abordaje planteado por la comunidad tomecina para proyectar sus espacios industriales de manera holística permite potenciar el desarrollo de una cadena de valor de sus elementos culturales, promoviendo su reutilización ya sea a través del turismo, circuitos patrimoniales, parques patrimoniales, fuentes de trabajo para la población local, etc., en definitiva, todo aquello que facilite su sostenibilidad (Méndez, Ciselli \& Rojas, 2016). Para ello resulta trascendental potenciar los ámbitos inmateriales desde la comunidad local, relevar la cultura del trabajo, la memoria colectiva, los saberes y oficios textiles, que constituyen el legado simbólico y principal motor de los procesos de patrimonialización.

La educación patrimonial resulta clave en este sentido, considerando que en el caso de Tomé es la propia ciudadanía la que ha liderado los procesos de valorización. La comunidad no sólo reconoce y proclama la defensa de patrimonio, sino que también se ha consolidado como un importante actor que puede proponer activamente alternativas de gestión y administración de estos espacios. La educación patrimonial permitiría promover el desarrollo local y también reforzar el conocimiento espacial e histórico que los habitantes poseen desde su propia experiencia con el lugar (Ibarra \& Ramírez, 2014, p. 41).

El movimiento social que se ha generado en torno a la Fábrica Bellavista marca el inicio de una nueva etapa en la gestión patrimonial, que permite profundizar el interés de distintos actores por proyectar los aspectos materiales e inmateriales del patrimonio industrial textil de Tomé. En este marco, se reconocen distintos imaginarios y sueños asociados al uso futuro que se le otorgará al sitio de la fábrica, los que a su vez, se tensionan con los intereses privados, siendo fundamental generar espacios de diálogo para conformar un plan de gestión patrimonial eficiente con un enfoque participativo (CEDEUS, 2016).

Finalmente, cabe subrayar que un desafío de este proyecto es la integración de la fábrica con el barrio aledaño y el resto del territorio tomecino. Los entrevistados proyectan que la rehabilitación de este inmueble industrial permitiría constituir un polo de desarrollo con una marcada identidad textil. Desde esta perspectiva, surge nuevamente la necesidad de buscar estrategias que permitan activar la articulación entre la fábrica con otras dimensiones y espacios asociados al patrimonio textil: los gimnasios, los sindicatos, el barrio, los clubes de fútbol, los talleres textiles, que son parte de la memoria industrial de Tomé. 


\section{REFERENCIAS}

Aliste, E., Almendras, A., \& Contreras, M. (2012). La dinámica del territorio en la conurbación Concepción-Talcahuano: huellas urbanas para una interpretación de las transformaciones ambientales durante la segunda mitad del siglo XX. Revista de geografía Norte Grande, 52, 5-18.

Alvarez, M. (2008). Patrimonio industrial: Un futuro para el pasado desde la visión europea. Apuntes, 21(1), 6-25.

Álvarez, F. (2016). Textil Bellavista Oveja Tomé pide cambiar uso de suelo para construir departamentos. Recuperado el 20 de junio de 2018, disponible en: http://www. economiaynegocios.cl/noticias/noticias.asp?id=236430

Álvarez, M. (2010). Patrimonio Industrial, Paisaje y Desarrollo Territorial. Áreas. Revista Internacional de Ciencias Sociales, 39, 21-29.

Bauman, Z. (2017). La globalización. Consecuencias humanas. México: Fondo de Cultura Económica (FCE).

Bengoa, J. (1999). La comunidad perdida. Santiago: LOM Ediciones.

Benito del Pozo, P. (2002). Patrimonio Industrial y cultura del territorio. Boletín de la A.G.E., 34, 213-227.

Bourdieu, P. (1998). La distinción. Criterio y bases sociales del gusto. Madrid: Taurus.

Carrión, F. (2010). El laberinto de las centralidades históricas en América Latina. Quito: Ministerio de Cultura del Ecuador.

Cartes, M., Luppi, R., \& López (2012). Bellavista Oveja Tomé: Una fábrica en el tiempo. Concepción: Ediciones Universidad San Sebastián.

Castells, M. (2015). Redes de Indignación y Esperanza. Madrid: Editorial Alianza.

Castells, M. (2003). La Era de la Información. Volumen II. El Poder de la Identidad. México: Ediciones Siglo XXI.

Centro de Desarrollo Urbano Sustentable (CEDEUS) (2016). Propuesta visión de futuro barrio Bellavista y fábrica Bellavista-Oveja Tomé. Recuperado el 20 de junio de 2018, disponible en: http://www.cedeus.cl/wp-content/uploads/2016/04/DocumentoPropuesta-Visi\%C3\%B3n-de-Futuro-Bellavista-Tom\%C3\%A91.pdf

Cifuentes, C. (2017). Fábrica Bellavista-Tomé: La lucha por la defensa del patrimonio como bien común. Recuperado el 6 de mayo de 2018, disponible en: https://www. eldesconcierto.cl/new/2016/08/09/rescatar-para-transformar-la-lucha-por-la-defensadel-patrimonio-como-bien-comun/

Colin, C. (2017). La nostalgia en la producción urbana: La defensa de barrios en Santiago de Chile. Revista INVI, 32, 91-111.

Consejo de Monumentos Nacionales (2013). Deportivo y cine Bellavista - Tomé. Recuperado el 15 de mayo de 2018, disponible en: http://www.monumentos.cl/monumentos/ monumentos-historicos/deportivo-cine-bellavista-tome 
Consejo de Monumentos Nacionales (2017). La Fábrica Bellavista Oveja Tomé es oficialmente Monumento Nacional. Recuperado el 20 de junio de 2018, disponible en: https://bit. ly/31P2u9z

Correa, C., Figueroa, A., Holt, J., Rolle, C., \& Vicuña, M. (2001). Historia del Siglo XX Chileno. Balance paradojal. Santiago de Chile: Editorial Sudamericana.

Corvalán, L. (1999). De lo vivido y lo peleado: memorias. Santiago: LOM Ediciones.

Dormaels, M. (2012). Identidad, comunidades y patrimonio local: una nueva legitimidad social. Alteridades, 22(43), 9-19.

García Canclini, N. (1999) Los usos sociales del patrimonio cultural, en Aguilar Criado, E Patrimonio Etnológico. Nuevas perspectivas de estudio. Consejería de Cultura, Junta de Andalucía, 16-33

Giddens, A. (1999). Un mundo desbocado. Madrid: Taurus.

González, N., \& Vera, J. (2009). Percepciones de los trabajadores sindicalizados de Bellavista Tomé y MACHASA Chiguayante ante el proceso de quiebras y nueva administración entre 1975-1990, Tesis para optar al grado de licenciado en Educación, Universidad de Concepción, Concepción.

Harvey, D. (1998). La condición de la posmodernidad. Buenos Aires: Ed. Amorrortu.

Hernández, R., Fernández, C., \& Baptista, P. (1998). Metodología de investigación. México: McGraw-Hill Editores.

Hernández, H. (1983). El gran Concepción: desarrollo histórico y estructura urbana. Primera parte. Génesis y evolución: de las fundaciones militares a la conurbación industrial. Investigaciones Geográficas, 30, 47-70.

Homobono, J. (2008). Del patrimonio cultural al industrial. Una mirada socioantropológica. Inx: Patrimonios culturales: Educación e interpretación. Cruzando límites y produciendo alternativas (pp. 57-74). XI Congreso de Antropología: retos teóricos y nuevas prácticas. Antropologia Kongresua: erronka teorikoak eta praktika berriak (12). Ankulegi Antropologia Elkartea.

Ibarra, M. (2015). El patrimonio industrial y su dimensión territorial. Emergencia, acuerdos y posibilidades. En L. Rojas, M. Carvajal \& A. Ortega (Eds.), Entre Rieles y Chimeneas: Un recorrido por el barrio obrero y ferroviario San Eugenio (pp. 17-22). Santiago: Consejo Nacional de la Cultura y las Artes.

Ibarra, M., \& Bonomo, U. (2012). De la fábrica a la vivienda. La protección de la memoria obrera en torno a la Fábrica Central de Leche, Santiago de Chile. Revista Apuntes, 25(1), 50-61.

Ibarra, M., \& Ramírez, C. (2014). Educación patrimonial en Chile. Una propuesta para el desarrollo de la identidad local. Revista América patrimonio educación patrimonial. 6, 39-47.

Ilustre Municipalidad de Tomé (2016). Plan de Desarrollo Comunal (PLADECO) Tomé. Recuperado el 10 de marzo de 2018, disponible en: http://static.tome.cl/pladeco_ 
tome_2016_2020.pdf

Irarrázaval, A. (2017). Hacia una gestión sustentable del patrimonio arquitectónico en Chile.

Recuperado el 23 de mayo de 2018, disponible en: http://www.cchc.cl/uploads/ archivos/archivos/Fundamenta_CChC_43.pdf

Jameson, F. (1995). El posmodernismo o la lógica cultural del capitalismo tardío. Barcelona: Paidós.

López, I., Bisbal, I., \& Aroztegui, C. (2015). Re fotografiando paisajes mineros para analizar el cambio: El caso del poblado minero de Lota en el sur de Chile. Arquitectura revista, 11(1), 11-21.

Márquez, F., Rozas, V., \& Arriagada, R. (2014). El lugar del patrimonio dominante. $A R Q$ (Santiago), 88, 56-65.

Matamala, F. J. (2016). Fábrica Bellavista Oveja Tomé. Colección privada, Consejo comunal para el Patrimonio- Tomé.

Méndez, P., Ciselli, G., \& Rojas, C. (2016). El patrimonio industrial petrolero en la Patagonia: Comodoro Rivadavia (Argentina) y Cerro Sombrero (Chile). Una perspectiva comparada. Pasos. Revista de Turismo y Patrimonio Cultural, 14(4), 981-997.

Ortiz, R. (2004). Mundialización y Cultura. Bogotá: Convenio Andrés Bello.

Osorio, J. (2018). Presentación Asociación Nacional de Barrios en VII Congreso Nacional de las Comunidades del Patrimonio en Antofagasta, 15-17 de Junio.

Pagola, L. \& Pérez, L. (2018). ¿Desindustrialización o reconfiguración industrial? impactos del ajuste neoliberal en el Gran Concepción (1973-1982). Manuscrito no publicado: un estudio de las experiencias participativas de uso y reapropiación del espacio industrial, Universidad de Concepción, Chile.

Patrimonio Tomé (2014). Consejo Comunal para el Patrimonio- Tomé. Recuperado el 20 de mayo de 2018, disponible en: http://patrimoniotome.blogspot.cl/2014/06/ consejocomunal-para-el-patrimonio-tome.html

Paulsen, A (2014) Negocios inmobiliarios, cambio socioespacial y contestación ciudadana en Santiago Poniente. El caso del barrio Yungay: 2000-2013. En R. Hidalgo \& M. Janoschka (Eds.), La Ciudad Neoliberal. Gentrificación y exclusión en Santiago de Chile, Buenos Aires, Ciudad de México y Madrid. Santiago de Chile/Madrid: Serie GEOlibros, Instituto de Geografía, Pontificia Universidad Católica de Chile; Departamento de Ciencia Política y Relaciones Internacionales, Universidad Autónoma de Madrid.

Pérez, L., \& Lagos, K. (2014). Formación y evolución urbana del barrio industrial Bellavista, Tomé. En J. Inzulza \& L. Pérez (Eds.), Teoría y Práctica del Diseño Urbano para la reflexión de la ciudad contemporánea (pp. 205-217). Santiago de Chile: Ediciones Universidad de Chile \& Universidad de Concepción.

Pérez, L., \& Matus, C. (2017). De la resistencia urbana al urbanismo ciudadano: Sujetos y estrategias patrimoniales en Concepción Metropolitano, Chile. Revista de Geografía Norte Grande, 66, 167-192. 
Pérez, S., Becker, E., Saavedra, M., \& Saldías, E. (2010). Bellavista: Memoria oral de un Pueblo Industrial. Recuperado el 20 de junio de 2018, disponible en: http://www. archivohistoricoconcepcion.cl/digital/bella1.pdf

Plan Regulador Comunal de Tomé (2008). Plan Regulador Comunal Tomé. Ilustre Municipalidad de Tomé.

Rebollo Cruz, M. (2017). Un acercamiento al patrimonio cultural inmaterial, su salvaguarda y patrimonialización. Campos en Ciencias Sociales, 5(1 y 2), 175-209.

Rojas Alcayaga, M. (2015). Dialéctica del patrimonio. Modernización y cultura activa en disputa. México: Ediciones Del Lirio.

Rojas Morales, L. (2013). Hacia el desarrollo sostenible de los barrios patrimoniales de Santiago de Chile. La comunidad como generadora de desarrollo en base al patrimonio cultural entre 1990 y 2012. Tesis de Maestría inédita. Pontificia Universidad Católica de Chile.

Rojas, M., \& Bustos, V. (2015). Valparaíso: el derecho al patrimonio. Antropologías Del Sur, 2(3), 155-173.

Sabaté, J. (2004). Paisajes culturales. El patrimonio como recurso básico para un nuevo modelo de desarrollo. Urban, 9, 8-29.

Sagaris, L. (2014). Citizen partiipation for sustanaible transport: the case of Living City in Santiago, Chile (1997-2012). Journal of Transport Geography, 41, 74-83

Sassen, S. (2007). Una Sociología de la Globalización. Buenos Aires: Editorial Katz.

Tribunal Constitucional (2017). Requerimiento de inaplicabilidad por inconstitucionalidad presentado por Bellavista Oveja Tomé SpA respecto del artículo 12 de la Ley N 17.288 sobre Monumentos Nacionales, en los autos sobre recurso de protección de que conoce la Corte de Apelaciones de Santiago, bajo el Rol N 36.624-2016.

Venegas Valdebenito, H., \& Morales Barrientos, D. (2017). Un caso de paternalismo industrial en Tomé: Familia, espacio urbano y sociabilidad de los obreros textiles (1920-1940). Historia (Santiago), 50(1), 273-302.

Villagra, A. (2014). Plan de Regeneración Integrada Urbana-Patrimonial Para el Centro Histórico de Tomé. Memoria Proyecto de Título 2014. Escuela de Arquitectura. Universidad de Chile. Santiago.

Wallerstein, I. (2005). Análisis de sistemas-mundo. Una introducción. México: Siglo XXI Editores. 